\title{
Effect of Different Mydriatic Regimens Used for Pupil Dilation on the Vital Signs of Premature Infants for Retinopathy of Prematurity Screening in a Philippine Tertiary Hospital: A Randomized Double-blind Clinical Trial
}

\author{
Roland Joseph D. Tan, MD, MS, ${ }^{1,2}$ David Marco M. Magpantay, MD² and Milagros H. Arroyo, MD, MPH',2 \\ ${ }^{1}$ Department of Ophthalmology and Visual Sciences, Philippines General Hospital, University of the Philippines Manila \\ ${ }^{2}$ College of Medicine, University of the Philippines Manila
}

\begin{abstract}
Objectives. To determine the safety and efficacy of three different mydriatic regimens in premature infants referred for retinopathy of prematurity (ROP) screening using (1) multiple alternate instillations of $0.5 \%$ cyclopentolate hydrochloride and $2.5 \%$ phenylephrine (MAI), (2) single instillation of $0.5 \% / 0.5 \%$ tropicamide + phenylephrine (SI) and (3) single instillation of $0.5 \% / 0.5 \%$ tropicamide + phenylephrine with a cotton wick placed in the inferior fornix (SIW) in a Philippine tertiary hospital.
\end{abstract}

Methods. A randomized, double-blind, clinical trial included preterm infants for ROP screening at a Philippine tertiary hospital. After instillations via MAI, SI, and SIW, systolic blood pressure (SBP), diastolic pressure (DBP), mean arterial pressure (MAP), heart rate, and oxygen saturation were monitored. Pupillary dilation was also measured.

Results. Sixty preterm infants, 20 to each intervention, were included. The MAI group did not have significant changes relative to its baseline vital signs. The use of SI produced lower DBP $(p<0.0106)$ and MAP $(p<0.0027)$ compared to MAI. The use of SI produced lower DBP $(p<0.01)$ and MAP $(p<0.003)$ compared to MAI. The SIW group exhibited significant increases in SBP $(p<0.002)$ and in MAP $(p<0.04)$ compared to MAI. This increase in SBP exceeded the clinical normal values for $<37$ weeks old infants. Pupillary dilation did not have significant differences among groups $(\mathrm{p}=0.24)$.

Conclusion. Due to significant increase in SBP, it is recommended to discontinue SIW in preterm infants for ROP screening since it may promote the mydriatic's systemic absorption. Except for the clinically increased heart rate in infants aged $\geq 37$ weeks at examination, SI was found to be at par with the recommendation of the UK ROP Guidelines of May 2008.

Keywords: preterm birth, tropicamide, phenylephrine, cyclopentolate, screening, ROP, retinopathy of prematurity, preterm infant

\section{INTRODUCTION}

Mydriatic drugs play a crucial role in the screening for retinopathy of prematurity (ROP) as it is needed for full visualization of the fundus, but they are associated with

Corresponding author: Roland Joseph D. Tan, MD, MS Department of Ophthalmology and Visual Sciences Philippines General Hospital

College of Medicine

University of the Philippines Manila

Taft Avenue, Ermita, Manila 1000, Philippines

Email: rdtan@up.edu.ph clinically significant adverse effects. The primary concern is systemic absorption, as $80 \%$ of the drug volume of the ocular preparations may enter the nasolacrimal duct and may be absorbed systemically via the nasal mucosa. ${ }^{1}$ Preterm infants are especially vulnerable due to their lower birth weights, reduced tear production, lower circulating blood 
volume, and immature drug metabolism and excretion systems. ${ }^{2-4}$ Complications involve the cardiovascular, respiratory, gastrointestinal, and central nervous systems. ${ }^{4}$ In screening for ROP, phenylephrine, cyclopentolate, and tropicamide are the most widely used and studied drugs, each associated with systemic effects. ${ }^{1,5}$ Various concentrations and combinations of the three drugs were evaluated and used in screening for ROP, where efficacies were measured via pupillary dilations or via successful visualization. ${ }^{1,4}$ An available recommendation for pupillary dilation is the United Kingdom ROP Guideline of May 2008 which recommends multiple alternate instillations of $0.5 \%$ cyclopentolate and $2.5 \%$ phenylephrine. ${ }^{1,6}$ However, cyclopentolate was not readily available in the Philippines; thus, the guideline was just used as the gold standard for the evaluation of the two mydriatic regimens commonly used in the country.

In the Philippines, the commercially available preparation of $0.5 \%$ tropicamide $+0.5 \%$ phenylephrine (Sanmyd, Santen, Osaka, Japan) is an easily obtained mydriatic regimen. One of its recommended dosage for mydriasis is a single instillation of two consecutive drops (roughly equivalent to $100 \mu \mathrm{L}$ ). ${ }^{7}$ However, single instillation of mydriatics poses challenges to local ophthalmologists due to the washout effect of crying and the limited surface area of the fornices, reducing the mydriasis. To address this, local ophthalmologists place cotton wicks in the inferior fornix to increase the retention and absorption of mydriatic drops. This was practiced in our institution, with the additional goal of lessening the dose required for mydriasis and a successful ROP screening. A study in Thailand evaluated the efficacy of cotton wick placed in the inferior fornix of premature infants and soaked in $0.5 \%$ cyclopentolate and $2.5 \%$ phenylephrine. ${ }^{8}$ The soaked cotton wicks produced a clinically significant increase in pupillary dilation for ROP screening, although its use was not preferred since the use of multiple alternate instillations of $0.5 \%$ cyclopentolate and $2.5 \%$ phenylephrine produced similar efficacy with less side effects. ${ }^{4,8}$

Considering the availability of $0.5 \%$ tropicamide + $0.5 \%$ phenylephrine (Sanmyd, Santen, Osaka, Japan) in the country and the limited studies on the use of cotton wicks, this study determined the safety and efficacy of two mydriatic regimens commonly used for premature infants referred for screening of ROP in our institution: single instillation (SI) of $0.5 \%$ tropicamide $+0.5 \%$ phenylephrine and single instillation of $0.5 \%$ tropicamide $+0.5 \%$ phenylephrine with a cotton wick (SIW) placed in the inferior fornix. These interventions were evaluated against multiple alternate instillations (MAI) of $0.5 \%$ cyclopentolate hydrochloride and $2.5 \%$ phenylephrine, the regimen recommended by the UK ROP Guidelines. ${ }^{1,6}$ Specifically, the study compared the changes in the systolic blood pressure (SBP), diastolic blood pressure (DBP), mean arterial pressure (MAP), heart rate, oxygen saturation and pupil dilation produced by the three described interventions. No study to date has determined which of these locally practiced mydriatic regimens is best suited for preterm infants for ROP screening, in terms of their safety and efficacy.

\section{METHODS}

This randomized, double-blind, clinical trial was approved by the Philippine General Hospital Ethics Review Board (OVS 2010-08-10-109) and with a ClinicalTrials. gov Identifier of NTC04838665. Informed consents from the parents or guardians of the participants were obtained. Preterm infants referred for ROP screening and cleared by the neonatology fellow from January to July 2011 were enrolled. The inclusion criteria were (1) birth weight of less than $1500 \mathrm{~g}$, (2) gestational age of 32 weeks or less, and (3) an unstable clinical course who are believed to be at high risk for ROP based on the ROP screening criteria set by the American Academy of Pediatrics. ${ }^{9}$ Infants with cardiac abnormalities directly affecting the heart rate and oxygen saturation, with inotropic medications, and with ventilatory support were excluded. The preterm infants were then randomly allocated to each intervention group.

The following data were collected for each patient: pediatric age, birth weight, diagnosis and co-morbidities. ECG pads were then placed accordingly, with the blood pressure (BP) cuff and pulse oximeter fitted snugly. Confounding factors such as hunger, cold temperature, and soiled diapers were addressed prior to monitoring. Baseline measurements of systolic BP (SBP), diastolic BP (DBP), mean arterial pressure (MAP), heart rate and oxygen saturation were automatically taken by a newly calibrated cardiac monitor (Phillips Digital IntelliVue MP20 junior, Koninklijke Philips Electronics N.V.) ten and five minutes prior to initial instillation of eye drops. Additional readings were taken one minute after a drop of proparacaine $\mathrm{HCl}$ $0.5 \%$ for the SIW intervention group to check if it also caused vital sign changes. Succeeding readings were then automatically taken by the cardiac monitor after the initial instillation of the mydriatics for the three regimens, then every after five minutes until the $45^{\text {th }}$ minute. The assigned mydriatic regimens were instilled as follows:

1. Multiple alternate instillations (MAI): alternate $0.1 \mathrm{~mL}$ (aspirated and contained in a $1 \mathrm{~mL}$ syringe) of $0.5 \%$ cyclopentolate hydrochloride Dilate ${ }^{\circledR}$ (Micro Labs Limited, Bangalore) and phenylephrine hydrochloride Mydfrin $^{\mathrm{TM}} 25 \mathrm{mg} / \mathrm{mL}$ (2.5\%) (Alcon, Fort Worth Texas) were instilled every five minutes in two doses (Figure 1A)

2. Single instillation (SI): only $0.1 \mathrm{~mL}$ aspirated and contained in a $1 \mathrm{~mL}$ syringe) of $0.5 \% / 0.5 \%$ tropicamide + phenylephrine hydrochloride Sanmyd-P (0.5\%/0.5\% Santen, Osaka, Japan) was instilled once (Figure 1B)

3. Single instillation with cotton wick (SIW): a cotton wick weighing $0.02 \mathrm{mg}$ (prepared using a digital weighing scale), soaked with $0.1 \mathrm{~mL}$ aspirated and contained in a $1 \mathrm{~mL}$ syringe) of $0.5 \% / 0.5 \%$ tropicamide + phenylephrine hydrochloride Sanmyd-P 0.5\%/0.5\% 
(Santen, Osaka, Japan) was placed on the lower fornix in each eye of the infant five minutes after a drop of proparacaine $\mathrm{HCl} 0.5 \%$ (Figure $1 \mathrm{C}$ ).

On the $45^{\text {th }}$ minute mark, a lid retractor was placed to photograph the pupil with a millimeter rule beside it. The first investigator administered the assigned mydriatics, ensured that the cardiac monitor was recording during the study monitoring time, placed the lid retractor, took a photo of the pupil with the ruler beside as a reference and returned the cardiac monitor from the neonatal intensive care unit to Sentro Oftalmogico Jose Rizal (SOJR). In the absence of a recording specially for the blood pressure, the first investigator pushed a button to repeat the measurement. A second investigator recorded all vital signs readings from the cardiac monitor in SOJR and measured the pupil dilation in the photo at another time.

The main outcomes were SBP, DBP, MAP, heart rate, oxygen saturation and pupil dilation. Since the normal values of SBP, DBP and HR differ between preterm and term infants, the participants were further grouped into preterm ( $<37$ weeks) and term ( $\geq 37$ weeks) based on their corrected age during the time they were monitored to assess clinical significance of the vital sign changes. There were infants born preterm who were referred or cleared for ROP screening only after reaching the corrected age of $\geq 37$ weeks. Data were tabulated using Microsoft Excel version 2016 (Microsoft Corporation, Redmond, Washington, USA) and subjected to statistical analysis using Shapiro-Wilk's test, repeated measures analysis of variance (AOV), Friedman's AOV by ranks, Kruskal-Wallis tests, Bonferroni and pairwise U-test.

\section{RESULTS}

\section{Baseline Characteristics and Baseline Vital Signs}

Sixty preterm infants, with 20 to each intervention (MAI, SI, and SIW) were included. The infants had a mean (SD) postnatal age of 37 (3) weeks, mean pediatric

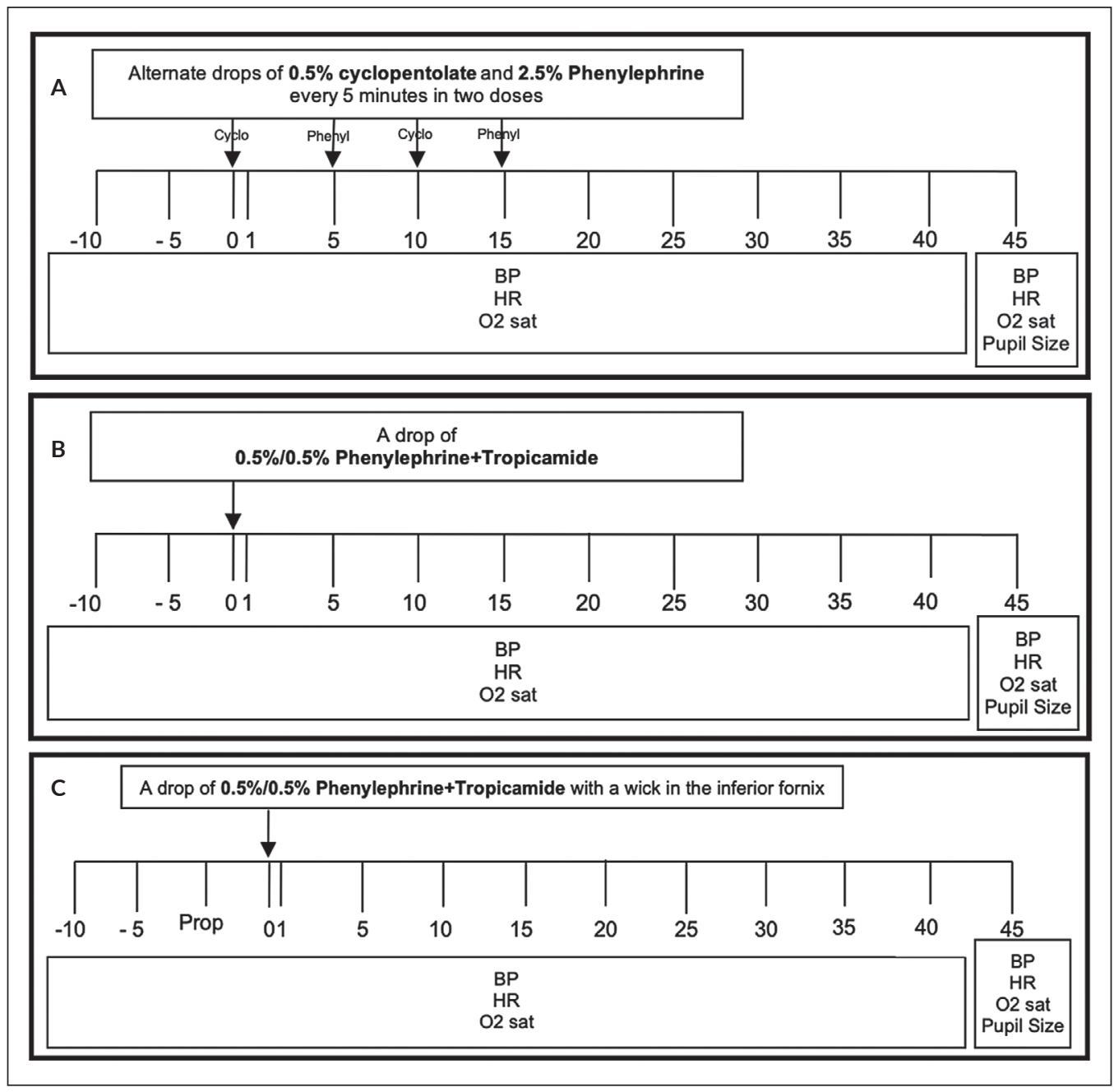

Figure 1. Mydriatic regimen for (A) multiple alternate instillation (MAI), (B) single instillation and (C) single instillation with cotton wick (SIW). 
age of 32 (2) weeks, mean corrective age of 37 (3) weeks and mean birthweight of 1243 (346) grams. Twenty eyes (17\%) in 11 infants (18\%) were diagnosed with different stages of ROP. Readings between 10 and 5 minutes prior to instillation in all intervention groups were not significantly different (Table 1). Readings between 5 minutes prior and after instillation of topical $0.5 \%$ proparacaine $\mathrm{HCl}$ in the SIW group were also not significantly different (Table 2).

\section{Vital Signs after Instillation}

The overall mean of SBP and overall medians of DBP and MAP were significantly different between each group while there were no significant differences in the overall medians of heart rate and oxygen saturation (Table 3).

Table 1. Baseline readings of vital signs according to intervention groups

\begin{tabular}{lcccc}
\multirow{2}{*}{ Vital Signs } & Treatment & \multicolumn{2}{c}{ Time (in minutes)* } & p-value \\
\cline { 3 - 4 } $\begin{array}{l}\text { Systolic BP } \\
\text { (mmHg) }\end{array}$ & MAI & $66.95(8.82)$ & $72.45(10.39)$ & 0.88 \\
& SI & $71.30(12.20)$ & $71.95(11.50)$ & \\
& SIW & $72.50(12.15)$ & $71.15(10.94)$ & \\
\hline Diastolic BP & MAI & $41.25(9.20)$ & $40.30(14.69)$ & 0.74 \\
(mmHg) & SI & $35.80(10.81)$ & $39.55(11.47)$ & \\
& SIW & $41.80(11.78)$ & $39.80(7.88)$ & \\
\hline Mean Arterial & MAI & $50.25(8.31)$ & $51.25(12.00)$ & 0.94 \\
Pressure & SI & $49.05(9.36)$ & $50.90(10.82)$ & \\
(mmHg) & SIW & $52.50(8.99)$ & $51.00(7.66)$ & \\
\hline Heart Rate & MAI & $156.70(16.69)$ & $155.10(15.00)$ & 0.78 \\
(bpm) & SI & $155.20(12.14)$ & $154.60(11.31)$ & \\
& SIW & $152.25(17.54)$ & $150.85(15.40)$ & \\
\hline Oxygen & MAI & $97.30(2.45)$ & $98.20(1.79)$ & 0.40 \\
Saturation & SI & $98.40(1.50)$ & $98.80(1.11)$ & \\
(\%) & SIW & $98.00(2.34)$ & $98.15(1.87)$ & \\
\hline
\end{tabular}

Notes: Mean (SD) values are given

*minutes prior to the first instillation of each intervention

MAI, Multiple alternate instillations; SI, Single instillation; SIW, Single instillation with wick; $B P$, blood pressure; $b p m$, beats per minute

Table 2. Difference in readings made five minutes $(-5)$ prior to instillation and after instillation of proparacaine $\mathrm{HCl}$ in the SIW group

\begin{tabular}{|c|c|c|c|}
\hline \multirow[b]{2}{*}{ Vital Signs } & \multicolumn{2}{|c|}{ Time } & \multirow[b]{2}{*}{ p-value } \\
\hline & -5 & $\begin{array}{c}\text { After } 0.5 \% \\
\text { Proparacaine } \mathrm{HCl}\end{array}$ & \\
\hline Systolic BP (mmHg) & 71.85 (10.78) & 73.05 (8.88) & 0.16 \\
\hline Diastolic BP (mmHg) & $39.88(11.49)$ & $42.90(10.19)$ & 0.38 \\
\hline $\begin{array}{l}\text { Mean Arterial Pressure } \\
(\mathrm{mmHg})\end{array}$ & $51.05(10.14)$ & $53.40(8.02)$ & 0.75 \\
\hline Heart Rate (bpm) & $153.50(13.92)$ & $151.30(16.01)$ & 0.35 \\
\hline Oxygen Saturation (\%) & $98.38(1.62)$ & $98.30(2.13)$ & 0.97 \\
\hline
\end{tabular}

Note: Mean (SD) values are given

SIW, Single instillation with wick; BP, blood pressure; bpm, beats per minute

\section{Systolic Blood Pressure}

The means for SBP on the $1^{\text {st }}$ minute after instillation and every 5 minutes from then on of MAI and SI groups had no significant difference from their baseline SBP $(-5)$ (Table 4). The over-all SBP mean of MAI and SI groups were also not significantly different from each other (Table 5). However, the over-all SBP means of MAI and SAI were significantly lower than SIW (Table 5). SIW also had significantly higher means for SBP compared to its baseline specifically at the $10^{\text {th }}$ to the $25^{\text {th }}$, and $40^{\text {th }}$ minute (Table 4 ).

\section{Diastolic Blood Pressure}

The medians of DBP on the $1^{\text {st }}$ minute after instillation and every 5 minutes from then on of the MAI and SI groups had no significant difference from their baseline medians of DBP (Table 6). SIW, on the other hand, produced significantly higher medians of DBP from its baseline at the $1^{\text {st }}$ and at the $10^{\text {th }}$ minute (Table 6). The over-all DBP medians of MAI and SIW groups were significantly higher than the SI group (Table 7).

\section{Mean Arterial Pressure}

The medians of MAP on the $1^{\text {st }}$ minute after instillation and every 5 minutes from then on of MAI and SI groups had no significant difference from their baseline medians of MAP (Table 8). SIW had a significantly higher medians of MAP on the $1^{\text {st }}$ and the $10^{\text {th }}$ minute compared to its baseline median of MAP (Table 8). The over-all MAP median of MAI group was significantly lower than SIW but significantly higher than SI (Table 9).

\section{Clinical Significance of Vital Sign Changes}

For MAI group, 7 infants were $<37$ weeks old during the time of monitoring while 13 were already aged $\geq 37$ weeks.

Table 3. The repeated-measures analysis of variance (AOV) of over-all means and medians of vital signs between intervention groups

\begin{tabular}{|c|c|c|c|c|}
\hline \multirow{2}{*}{$\begin{array}{l}\text { Vital Sign } \\
\text { Parameter }\end{array}$} & \multicolumn{3}{|c|}{ Treatment } & \multirow{2}{*}{ p-value } \\
\hline & MAI & SI & SIW & \\
\hline $\begin{array}{l}\text { Systolic BP } \\
(\mathrm{mmHg})^{\dagger}\end{array}$ & $\begin{array}{c}73.85 \\
(11.72)\end{array}$ & $\begin{array}{c}72.44 \\
(14.16)\end{array}$ & $\begin{array}{c}78.20 \\
(12.57)\end{array}$ & 0.0040 \\
\hline $\begin{array}{l}\text { Diastolic BP } \\
(\mathrm{mmHg})^{\ddagger}\end{array}$ & $\begin{array}{c}40 \\
(34,47) \\
\end{array}$ & $\begin{array}{c}37 \\
(32,44)\end{array}$ & $\begin{array}{c}41 \\
(35,48) \\
\end{array}$ & 0.0001 \\
\hline $\begin{array}{l}\text { Mean Arterial } \\
\text { Pressure }(\mathrm{mmHg})^{\ddagger}\end{array}$ & $\begin{array}{c}52 \\
(46,58)\end{array}$ & $\begin{array}{c}48 \\
(43,54.5)\end{array}$ & $\begin{array}{c}53 \\
(48,60.5)\end{array}$ & 0.0001 \\
\hline $\begin{array}{l}\text { Heart Rate } \\
(\mathrm{bpm})^{\ddagger}\end{array}$ & $\begin{array}{c}148 \\
(141,163.5)\end{array}$ & $\begin{array}{c}154 \\
(144,161) \\
\end{array}$ & $\begin{array}{c}149 \\
(133.5,162)\end{array}$ & 0.0900 \\
\hline $\begin{array}{l}\text { Oxygen } \\
\text { Saturation (\%) }\end{array}$ & $\begin{array}{c}99 \\
(97,100)\end{array}$ & $\begin{array}{c}99 \\
(98,100)\end{array}$ & $\begin{array}{c}99 \\
(97,100)\end{array}$ & 0.9384 \\
\hline
\end{tabular}

Notes: All shaded boxes have significant $p$-values.

+ Mean (SD) of systolic BP

¥ Median (inter-quartile range, IQR; $25 \%$ to $75 \%$ ) of diastolic BP, mean arterial pressure, heart rate, and oxygen saturation

MAI, Multiple alternate instillations; SI, Single instillation; SIW, Single instillation with wick; $B P$, blood pressure; bpm, beats per minute 
Table 4. Pairwise comparison of mean systolic blood pressure of Multiple Alternate Instillation, Single Instillation, and Single Instillation with Wick to baseline (-5)

\begin{tabular}{ccccccccc}
$\begin{array}{c}\text { Time } \\
\text { (min) }\end{array}$ & \multicolumn{3}{c}{ MAI } & & \multicolumn{2}{c}{ SI } & & \multicolumn{2}{c}{ SIW } \\
\cline { 2 - 4 } \cline { 7 - 8 } \cline { 7 - 8 } & Mean (SD) SBP & p-value & & Mean (SD) SBP & p-value & & Mean (SD) SBP & p-value \\
\hline-5 & $72.45(10.12)$ & & & $71.95(11.21)$ & & & $71.15(10.66)$ & \\
\hline 1 & $75.40(10.50)$ & 0.205 & & $77.35(13.71)$ & 0.099 & & $77.95(14.87)$ & 0.270 \\
\hline 5 & $76.85(11.24)$ & 0.090 & & $76.20(17.29)$ & 0.306 & & $80.3(11.06)$ & 0.240 \\
\hline 10 & $75.30(11.07)$ & 0.327 & $75.90(15.02)$ & 0.326 & & $81.20(10.68)$ & 0.001 \\
\hline 15 & $77.20(10.02)$ & 0.089 & $71.30(15.03)$ & 0.845 & & $77.70(12.09)$ & 0.020 \\
\hline 20 & $73.00(12.20)$ & 0.869 & $69.60(11.70)$ & 0.399 & $79.85(13.06)$ & 0.001 \\
\hline 25 & $71.40(10.89)$ & 0.564 & $71.55(10.46)$ & 0.878 & $79.70(13.01)$ & 0.005 \\
\hline 30 & $70.70(14.62)$ & 0.620 & $69.55(12.91)$ & 0.359 & $76.40(12.92)$ & 0.110 \\
\hline 35 & $73.15(10.63)$ & 0.757 & $72.20(13.40)$ & 0.920 & $76.30(13.73)$ & 0.100 \\
\hline 40 & $72.40(13.84)$ & 0.985 & $72.60(14.19)$ & 0.844 & $76.45(11.44)$ & 0.040 \\
\hline 45 & $73.10(8.74)$ & 0.706 & $68.15(13.14)$ & 0.240 & $76.10(10.43)$ & 0.080 \\
\hline
\end{tabular}

Note: All shaded boxes have significant $p$-values.

MAI, Multiple alternate instillations; SI, Single instillation; SIW, Single instillation with wick; SBP, systolic blood pressure

Table 6. Pairwise comparison of median diastolic blood pressure of Multiple Alternate Instillation, Single Instillation, and Single Instillation with Wick to baseline

\begin{tabular}{|c|c|c|c|c|c|c|}
\hline \multirow{2}{*}{$\begin{array}{l}\text { Time } \\
\text { (min) }\end{array}$} & \multicolumn{2}{|l|}{ MAI } & \multicolumn{2}{|l|}{ SI } & \multicolumn{2}{|c|}{ SIW } \\
\hline & $\begin{array}{l}\text { Median } \\
\text { (IQR) DBP }\end{array}$ & p-value & $\begin{array}{l}\text { Median } \\
\text { (IQR) DBP }\end{array}$ & $p$-value & $\begin{array}{l}\text { Median } \\
\text { (IQR) DBP }\end{array}$ & p-value \\
\hline-5 & $37(31,49)$ & & $37(33,41)$ & & $40(33,45)$ & \\
\hline 1 & $41.5(37,54)$ & 0.47 & $37(34,47)$ & 0.46 & $44(40,50)$ & 0.010 \\
\hline 5 & $42.5(36,49)$ & 0.44 & $40(34,50)$ & 0.20 & $40(33,45)$ & 0.580 \\
\hline 10 & $42(37,50)$ & 0.17 & $38.5(30,40)$ & 0.57 & $48(42,56)$ & 0.004 \\
\hline 15 & $40(33,45)$ & 0.90 & $34(30,38)$ & 0.50 & $39(35,45)$ & 0.650 \\
\hline 20 & $39.5(29,42)$ & 0.93 & $35(29,39)$ & 0.30 & $39(34,43)$ & 0.920 \\
\hline 25 & $43.5(31,47)$ & 0.49 & $37.5(32,43)$ & 0.55 & $41(35,43)$ & 0.430 \\
\hline 30 & $40(32,44)$ & 0.77 & $34.5(33,41)$ & 0.73 & $34(31,52)$ & 0.580 \\
\hline 35 & $39.5(33,43)$ & 0.80 & $37.5(34,49)$ & 0.51 & $38(35,45)$ & 0.480 \\
\hline 40 & $41.5(34,43)$ & 0.96 & $36(33,44)$ & 0.72 & $40(35,43)$ & 0.880 \\
\hline 45 & $40(36,46)$ & 0.97 & $35.5(32,43)$ & 0.90 & $44(39,49)$ & 0.140 \\
\hline
\end{tabular}

Note: All shaded boxes have significant $p$-values.

Median (inter-quartile range, IQR; $25 \%$ to $75 \%$ )

MAI, Multiple alternate instillations; SI, Single instillation; SIW, Single instillation with wick; $D B P$, diastolic blood pressure

Eight infants were $<37$ weeks old from the SI group while 7 infants were $<37$ weeks old from the SIW group. There was an increase in the SBP means in $<37$ weeks old infants assigned to the SIW group as compared to its supposed clinical normal range (Table 10). ${ }^{10,11}$ The DBP of the mydriatic regimens, on the other hand, were all below the set normal range for the $\geq 37$ weeks old infants. ${ }^{11,12}$ However, the values were still allowable and accepted based on Hegyi et al. who set the lower DBP cutoff at $25 \mathrm{mmHg}{ }^{13,14}$ Heart rates for infants $\geq 37$ weeks were higher in SI and SIW groups compared to normal values. ${ }^{15}$
Table 5. Pairwise comparison of over-all means of systolic blood pressure according to the intervention group

SBP Comparison (Mean, SD) (mmHg) p-value

MAI $(73.85,2.29)$ vs. SI $(72.44,2.75) \quad 1.0000$

MAI (73.85, 2.29) vs SIW $(78.20,2.03) \quad 0.0020$

$\operatorname{SIW}(78.20,2.03)$ vs. SI $(72.44,2.75) \quad 0.0001$

Note: All shaded boxes have significant $p$-values. MAI, Multiple alternate instillations; SI, Single instillation; SIW, Single instillation with wick

Table 7. Pairwise comparison of diastolic blood pressure medians according to intervention group

\begin{tabular}{cc}
$\begin{array}{c}\text { DBP Comparison } \\
\text { (Median, IQR) (mmHg) }\end{array}$ & p-value \\
\hline MAI (40 [34,47]) vs. SIW (41 [35,48]) & 0.430 \\
\hline MAI (40 [34,47]) vs. SI (37 [32,44]) & 0.010 \\
\hline SIW $(41[35,48])$ vs. SI (37 [32,44]) & 0.001 \\
\hline
\end{tabular}

Note: All shaded boxes have significant $p$-values. Median (inter-quartile range, IQR; $25 \%$ to $75 \%$ ) MAI, Multiple alternate instillations; SI, Single instillation; SIW, Single instillation with wick; DBP, diastolic blood pressure 
Table 8. Pairwise comparison of median MAP of MAI, SI and SIW to baseline

\begin{tabular}{|c|c|c|c|c|c|c|}
\hline \multirow{2}{*}{$\begin{array}{l}\text { Time } \\
\text { (min) }\end{array}$} & \multicolumn{2}{|l|}{ MAI } & \multicolumn{2}{|l|}{ SI } & \multicolumn{2}{|l|}{ SIW } \\
\hline & $\begin{array}{l}\text { Median } \\
\text { (IQR) MAP }\end{array}$ & p-value & $\begin{array}{l}\text { Median } \\
\text { (IQR) MAP }\end{array}$ & p-value & $\begin{array}{l}\text { Median } \\
\text { (IQR) MAP }\end{array}$ & $p$-value \\
\hline-5 & $50(41,57)$ & & $47.5(43,54)$ & & $50.5(47,54)$ & \\
\hline 1 & $54(47,60)$ & 0.333 & $49.5(46,54)$ & 0.461 & $57.5(52,61)$ & 0.005 \\
\hline 5 & $54.5(48,60)$ & 0.238 & $49.5(46,56)$ & 0.203 & $54.5(50,58)$ & 0.424 \\
\hline 10 & $52.5(45,60)$ & 0.165 & $47.5(45,53)$ & 0.566 & $59(53,68)$ & 0.001 \\
\hline 15 & $52.5(48,56)$ & 0.502 & $44(42,53)$ & 0.497 & $53(48,57)$ & 0.224 \\
\hline 20 & $52(42,57)$ & 0.823 & $47(42,53)$ & 0.302 & $51(45,59)$ & 0.174 \\
\hline 25 & $51.5(44,56)$ & 0.569 & $48.5(43,53)$ & 0.546 & $51(49,57)$ & 0.102 \\
\hline 30 & $50(44,55)$ & 0.691 & $48(40,54)$ & 0.733 & $50(44,55)$ & 0.518 \\
\hline 35 & $48(47,52)$ & 0.920 & $51(43,55)$ & 0.505 & $53(47,55)$ & 0.268 \\
\hline 40 & $52(46,55)$ & 0.966 & $48(42,54)$ & 0.718 & $52(47,57)$ & 0.410 \\
\hline 45 & $52(48,56)$ & 0.907 & $46.5(42,55)$ & 0.895 & $54(49,61)$ & 0.079 \\
\hline
\end{tabular}

Note: All shaded boxes have significant $p$-values.

Median (inter-quartile range (IQR); $25 \%$ to $75 \%$ )

MAI, Multiple alternate instillations; SI, Single instillation; SIW, Single instillation with wick; MAP, mean arterial pressure

Table 10. Comparison of systolic and diastolic blood pressure and heart rate between intervention groups against normal values

\begin{tabular}{|c|c|c|c|c|c|}
\hline $\begin{array}{l}\text { Vital } \\
\text { Sign }\end{array}$ & $\begin{array}{l}\text { Postnatal } \\
\text { age }\end{array}$ & Normal $^{10,11}$ & MAI & SI & SIW \\
\hline \multirow{2}{*}{$\begin{array}{l}\text { SBP } \\
(\mathrm{mmHg})\end{array}$} & $<37$ weeks & $55-75^{12}$ & $74 \pm 6$ & $70 \pm 8$ & $76 \pm 9$ \\
\hline & $\geq 37$ weeks & $65-85$ & $74 \pm 8$ & $74 \pm 12$ & $79 \pm 9$ \\
\hline \multirow{2}{*}{$\begin{array}{l}\text { DBP } \\
(\mathrm{mmHg})\end{array}$} & $<37$ weeks & $35-45^{12}$ & $42(39,46)$ & $40(38,44)$ & $0(38,44)$ \\
\hline & $\geq 37$ weeks & $45-55$ & $41(36,46)$ & $36(35,44)$ & $42(40,44)$ \\
\hline \multirow{2}{*}{$\begin{array}{l}\text { Heart } \\
\text { rate } \\
\text { (bpm) }\end{array}$} & $<37$ weeks & $120-170^{15}$ & $\begin{array}{c}148 \\
(143,162)\end{array}$ & $\begin{array}{c}156 \\
(144,166)\end{array}$ & $\begin{array}{c}148 \\
(143,154)\end{array}$ \\
\hline & $\geq 37$ weeks & $100-150^{15}$ & $\begin{array}{c}150 \\
(146,152) \\
\end{array}$ & $\begin{array}{c}155 \\
(146,157) \\
\end{array}$ & $\begin{array}{c}154 \\
(129,164)\end{array}$ \\
\hline
\end{tabular}

Note: All shaded boxes have values outside the normal range.

MAI, Multiple alternate instillations; SI, Single instillation; SIW, Single instillation with wick; SBP, Systolic blood pressure; DBP, Diastolic blood pressure; bpm, beats per minute

\section{DISCUSSION}

This study determined the safety and efficacy of single instillation (SI) of $0.5 \%$ tropicamide $+0.5 \%$ phenylephrine and single instillation of $0.5 \%$ tropicamide $+0.5 \%$ phenylephrine with a cotton wick (SIW) placed in the inferior fornix and evaluated against multiple alternate instillations (MAI) of $0.5 \%$ cyclopentolate hydrochloride and 2.5\% phenylephrine. It was ensured that there were no differences in baseline vital signs readings across the three mydriatic regimens to establish that the changes noted during intervention phase were from the mydriatic regimens only.

The MAI regimen produced no significant changes compared to its baseline SBP, DBP, and MAP. SBP, DBP and heart rate were within the clinical normal range. ${ }^{10-15}$ The resulting mean pupil diameter allowed successful ROP
Table 9. Pairwise comparisons of MAP medians according to intervention group

\begin{tabular}{cc}
\hline $\begin{array}{c}\text { MAP Comparison, } \\
\text { Median (IQR) (mmHg) }\end{array}$ & p-value \\
\hline MAI - 52 (46,58) vs. SI - 48 (43,54) & 0.0030 \\
\hline MAI - 52 (46,58) vs. SIW - $53(48,60.5)$ & 0.0400 \\
\hline SIW - 53 (48,61) vs. SI - 48 (43,54) & 0.0001 \\
\hline
\end{tabular}

Note: All shaded boxes have significant $p$-values. Median (inter-quartile range (IQR); $25 \%$ to $75 \%$ ) MAI, Multiple alternate instillations; SI, Single instillation; SIW, Single instillation with wick; MAP, mean arterial pressure screening. With the SI regimen, the DBP and MAP were significantly lower relative to the MAI regimen. The heart rate was also clinically elevated for infants who were $\geq 37$ weeks old. ${ }^{15}$ However, variability of heart rate was less compared to SIW (Table 10). There was also no significant change in DBP and MAP from baseline. This result is similar to previous studies which also demonstrated no increase in the blood pressure even when higher concentrations of the drugs were already used. ${ }^{16}$ Blood pressures were within the set allowable range clinically. ${ }^{10-14}$ The resulting mean pupil diameter also allowed successful screening similar to the MAI regimen.

Significant increases in the SBP and MAP were observed in the SIW regimen compared to both baseline and to the MAI regimen. ${ }^{12}$ Since the same combination of mydriatic drugs and concentration were used as the SI group but had different effects, the vital sign changes in SIW regimen were likely attributable to the cotton wick. The mean pupillary dilation by the SIW regimen was the highest among the interventions at $5.09 \mathrm{~mm}$ but was not statistically and clinically significant compared to MAI and SI regimen. This finding is in contrasts with Thanathanee et al.'s study where they found that the use of cotton wick albeit with a different mydriatic agent combination produced clinically significant increase in pupillary dilation compared to a regimen without it. ${ }^{8}$

The significant vital sign changes associated with the use of cotton wick can be explained by the cotton wool absorbing additional amount of the mydriatics in addition to the normal volume absorbed by the fornices. The cotton wick served as a depot as planned to produce increased pupil dilations, ${ }^{8}$ as it increases the contact time between the mydriatic, the cornea, and the conjunctiva, circumventing the problem with the limited volume of fornices in preterm 
infants. Also, preterm infants have reduced reflex tear secretion, allowing topically applied medication to become more concentrated, more so that a depot existed. ${ }^{3}$ However, the increased contact time, drug concentrations and volume offered by the cotton wick may also have increased the amount of mydriatics draining into the nasolacrimal duct causing enhanced systemic absorption. This can account for the increased systemic side effects. Aside from this, the cotton wick may also have induced constant local irritation in the preterm infants' eyes since it was left in place for 45 minutes. Its duration in the lower fornix was longer than the known anesthetic effect of $0.5 \%$ proparacaine $\mathrm{HCl}$ of around 15 minutes only which was instilled prior to the placement of the cotton wick. ${ }^{17}$ The local irritation could have been an added reason for the increase in SBP, DBP, MAP and heart rate.

The evaluation of the two regimens used locally against the United Kingdom ROP Guideline of May 2008 recommendation of MAI demonstrated that the SI group produced an almost similar efficacy in pupillary dilation and safety to the MAI regimen and produced less changes in vital signs compared to SIW group. Considering the availability of mydriatic medications in the country, it is then recommended that the SI regimen be used and that the SIW regimen be discontinued in pupillary dilation of infants for ROP screening.

\section{CONCLUSION}

The use of single instillation of $0.5 \% / 0.5 \%$ tropicamide + phenylephrine with cotton wick (SIW) was shown to cause statistically and clinically significant increase in SBP and clinically significant increase in heart rate. It is recommended to discontinue its use as it enhances the systemic absorption of the mydriatic medications giving rise to the described increase in vitals sign changes. Except for the clinically increased heart rate in term infants, the single instillation of $0.5 \% / 0.5 \%$ tropicamide + phenylephrine (SI) was found to be at par with the recommendation of the UK ROP Guidelines of May 2008 and due to availability concerns, is then recommended to be used in the pupillary dilation for ROP screening in the Philippines.

\section{Statement of Authorship}

All authors participated in the data collection and analysis and approved the final version submitted.

\section{Author Disclosure}

All authors declared no conflicts of interest.
Funding Source

No funding support.

\section{REFERENCES}

1. Kremer L, Reith D, Medlicott N, Broadbent R. Systematic review of mydriatics used for screening of retinopathy in premature infants. BMJ Pediatr Open. 2019; 3(1):e000448.

2. Rosales T, Isenberg S, Leake R, Everett S. Systemic effects of mydriatics in low weight infants. J Pediatr Ophthalmol Strabismus. 1981; 18(6):42-4.

3. Isenberg S. Development of tearing in preterm and term neonates. Arch Ophthalmol. 1998; 116(6):773.

4. Neffendorf J, Mota P, Xue K, Hildebrand G. Efficacy and safety of phenylephrine $2.5 \%$ with cyclopentolate $0.5 \%$ for retinopathy of prematurity screening in 1246 eye examinations. Eur J Ophthalmol. 2014; 25(3):249-53.

5. Yazdani N, Sadeghi R, Momeni-Moghaddam H, Zarifmahmoudi L, Ehsaei A. Comparison of cyclopentolate versus tropicamide cycloplegia: a systematic review and meta-analysis. J Optom. 2018; 11(3):135-43.

6. Wilkinson A, Haines L, Head K, Fielder A. UK retinopathy of prematurity guideline. Eye. 2008; 23(11):2137-9.

7. MIMS Philippines. Sanmyd-P Full Prescribing Information, Dosage \& Side Effects [Internet]. 2021 [cited 2021 Jan]. Available from: https://www.mims.com/philippines/drug/info/sanmyd-p?type=full

8. Thanathanee O, Ratanapakorn T, Morley M, Yospaiboon Y. Lower conjunctival fornix packing for mydriasis in premature infants: a randomized trial. Clin Ophthalmol. 2012; 6:253-2.

9. American Academy of Pediatrics. Section on ophthalmology screening examination of premature infants for retinopathy of prematurity. Pediatrics. 2001; 108(3):809-11.

10. Luthra M. Manual of Pediatric Intensive Care. Chennai: Elsevier Health Sciences APAC; 2014.

11. Kliegman R, Stanton B, Geme J, Schor N, Behrman R. Nelson Textbook of Pediatrics. 19th ed. Philadelphia: Elsevier/Saunders; 2011.

12. American Heart Association. ECC Guidelines Part 10: Pediatric advanced life support. Circulation. 2000; 102(suppl_1).

13. Gomella T, Cunningham M, Eyal F. Gomella's Neonatology: Management, Procedures, On-Call Problems, Diseases, and Drugs. 7th ed. China: McGraw-Hill Medical; 2013.

14. Hegyi T, Carbone MT, Anwar M, Ostfeld B, Hiatt M, Koons A, et al. Blood pressure ranges in premature infants. I. The first hours of life. J Pediatr. 1994; 124(4):627-33.

15. Dieckmann R, Brownstein D, Gausche-Hill M (eds): Pediatric Education for Prehospital Professionals. Sudbury, Mass, Jones \& Bartlett, American Academy of Pediatrics, 2000, pp 43-45.

16. Rush R, Rush S, Nicolau J, Chapman K, Naqvi M. Systemic manifestations in response to mydriasis and physical examination during screening for retinopathy of prematurity. Retina. 2004; 24(2):242-5.

17. Marsh V, Young W, Dunaway K, Kissling G, Carlos R, Jones S, et al. Efficacy of topical anesthetics to reduce pain in premature infants during eye examinations for retinopathy of prematurity. Ann Pharmacother. 2005; 39(5):829-33. 